\title{
Chatbot aplicado a projeto de pesquisa científica: Uma proposta para melhoria do SARA
}

\author{
Marco Antônio Leal Lobão ${ }^{1}$, Luiz Gustavo Pereira Lima Santos', Layse Santos \\ Souza $^{2}$ \\ ${ }^{1}$ Universidade Tiradentes (Unit) \\ Aracaju - SE - Brasil \\ ${ }^{2}$ Universidade Federal de Sergipe (UFS) \\ São Cristovão - SE - Brasil \\ marco.lealesouunit.com.br, luiz.plima@souunit.com.br, \\ laysesantossouza@gmail.com
}

\begin{abstract}
SARA (Administrative System of Academic Resources) is a management software that acts as a manager of scientific initiation research projects. This work proposes the improvement of SARA through the implementation of a chatbot, therefore, the proposed objective is to improve the user's communication with the software by helping in the process of research registration, indicating other research or researchers as reference.
\end{abstract}

Resumo. SARA (Sistema Administrativo de Recursos Acadêmicos) é um software de gestão que atua como gerenciador dos projetos de pesquisa de iniciação científica. Este trabalho propõe a melhoria do SARA através da implementação de um chatbot, logo, o objetivo proposto é melhorar a comunicação do usuário com o software por meio de ajuda no processo de cadastro de pesquisas, indicando outras pesquisas ou pesquisadores como referência.

\section{Introdução}

SARA é uma plataforma de software de gestão que integra coordenadores, pesquisadores e discentes (orientandos) de uma universidade particular do nordeste do Brasil. O intuito do SARA é receber projetos de pesquisa, cadastrar informações e documentos relacionados aos projetos, classificá-los como reprovados, aprovados com ou sem bolsa, e enviar notificações aos pesquisadores acerca dos projetos aprovados para que os pesquisadores possam cadastrar os discentes que irão participar do projeto. Além disso, o SARA dispõe de um painel de discentes para que estes enviem seus relatórios (mensais, trimestrais, semestrais ou anuais), para os pesquisadores aprovarem e encaminharem à coordenação de pesquisa.

No SARA foi realizado um upgrade na interface visando adequar novas informações e aplicar técnicas de Inteligência Artificial, isto é, chatbot (sistema de diálogos inteligentes) para interagir com os usuários. A integração entre SARA e chatbot tem como propósito expandir e melhorar o acesso às informações relativas aos projetos de pesquisa. Essa integração permite agregar estratégias para apoiar a tomada de decisões, ampliar o relacionamento entre coordenadores, pesquisadores e discentes, 
catalogar informações, por exemplo, campos de pesquisa e publicações para auxiliar a pesquisa com base nos resultados.

\section{Descrição do chatbot}

O chatbot está em processo de desenvolvimento e será integrado ao SARA para auxiliar coordenadores, pesquisadores e discentes nas dúvidas acerca dos projetos de pesquisa e como utilizar o upgrade do SARA. Uma das funcionalidades do chatbot é o cadastro de projetos de pesquisa através de um "bate papo", por exemplo, durante o "bate papo" entre chatbot e usuário podem ser realizadas perguntas, solicitações de informações e/ou documentos necessários para o cadastro de um projeto.

Para o seu desenvolvimento foram escolhidas a linguagem PHP em razão do baixo custo de manutenção e a linguagem AIML em razão da criação de diálogos parecidos com a linguagem natural, e da integração com o Program-O (PHP MySQL AIML Chatbot) por oferecer recursos para criar e gerir chatbots.

O Program-O foi modificado para o chatbot proposto por não receber mais atualizações e manifestar erros, por exemplo, erros que impediam o funcionamento do sistema. Dentre as diversas ferramentas do Program-O foram utilizadas um log com as entradas desconhecidas em uma conversa, visando facilitar o "debug" e o treinamento do chatbot; um log de conversas para armazenar as conversas visando facilitar tanto a análise quanto o "debug" do chatbot; uma lista com todos os patterns de AIML registrados, para auxiliar na avaliação do estado atual de treinamento do chatbot; uma interface para facilitar o processamento das entradas e saídas do chatbot através da adição de patterns do AIML; e, uma interface de testes para armazenar um ID de conversa com o propósito de facilitar o registro e análise dessas informações.

Figura 1 ilustra a interface de teste do chatbot através de um sistema de AIML, que por meio de perguntas realizadas pelos usuários são geradas respostas ou ações préprogramadas.

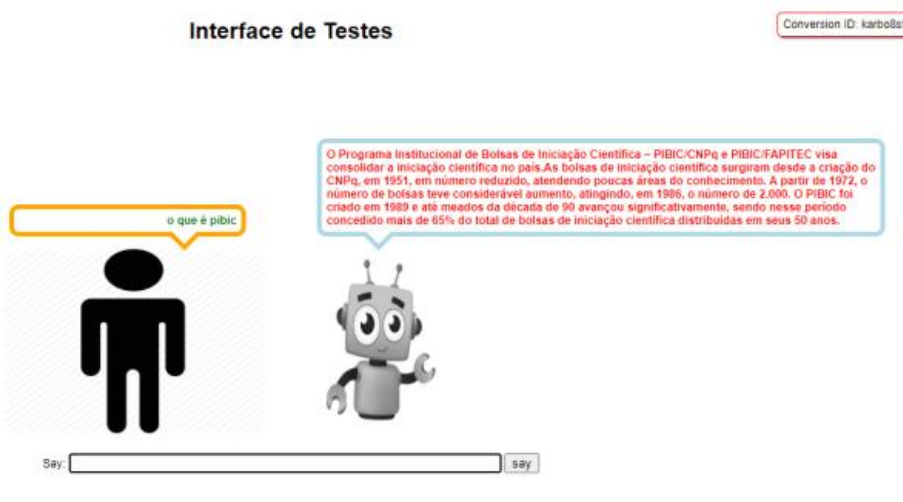

Fig. 1: Teste de interface do chatbot Fonte: Elaborado pelos autores 


\section{Considerações Finais}

Muitos usuários acabam tendo dificuldades com o uso da interface, dessa forma, o chatbot integrado ao SARA está sendo desenvolvido com o intuito de melhorar o SARA e facilitar a usabilidade, bem como diminuir a carga de trabalho da coordenação de pesquisa, pois o chatbot pode ser treinado para responder perguntas comuns.

Tendo em vista esses aspectos percebe-se que ao final desse projeto, o SARA será um ecossistema completo de pesquisa que permite gerenciar e integrar dados auxiliando os pesquisadores no controle e na inovação da pesquisa em Iniciação Científica, assim como, determinar níveis razoáveis de segurança e viabilidade.

Como trabalhos futuros pretende-se implementar um sistema de recomendação visando facilitar o acesso e/ou cadastro e/ou identificação de pesquisas futuras, implantar um corretor automático para corrigir erros comuns na escrita da língua portuguesa, e melhorar o processamento de texto visando o desempenho do SARA.

\section{Referências}

SARA - Sistema Administrativo de Recursos Acadêmicos. Disponivel em: http://www.saraic.net/. Acesso em: 09 out. 2020

VILLAR, Victor Brito; RODRIGUEZ, Guillermo; ROCHA, Fábio Gomes. Interaction with Intelligent Conversation Agents: A case study. 6to Congreso Nacional de Ingeniería Informática - Sistemas de Información - CoNaIISI, 2018.

SHAWAR, Bayan Abu; ATWELL, Eric. Chatbots: are they really useful? In: Ldv forum. 2007. p. 29-49.

Program O AI Chatbot. Disponivel em: https://www.program-o.com/. Acesso em: 05 dez. 2019 